\title{
O comportamento dos usuários docentes frente à Arquitetura da Informação (AI) do SIGAA
}

\section{Maria de Fátima Oliveira Costa}

Docente do Departamento de Ciências da Informação (DCI) e do Programa de Pós-Graduação em Ciência da Informação da Universidade Federal do Ceará (PPGCI/UFC). Doutora em Ciência da Informação, pela Universidade Estadual Paulista (UNESP). Mestra em Ciência da Informação pela Universidade Federal da Paraíba (UFPB). Bacharela em Biblioteconomia. nela UJF.

fatimaocosta@yahoo.com.br

\section{Oswaldo de Souza}

Docente do Departamento de Ciências da Informação (DCI) e do Programa de Pós-Graduação em Ciência da Informação da Universidade Federal do Ceará (PPGCI/UFC). Doutor e Mestre em Engenharia de Teleinformática, pela Universidade Federal do Ceará (UFC). Bacharel em Informática, pela I Inivercidade de Fortaleza (I INIFOR)

\section{ovsouza@gmail.com}

\section{Adriana Nóbrega da Silva}

Docente do Departamento de Ciências da Informação (DCI) da Informação da Universidade Federal do Ceará (UFC). Mestra em Ciência da Informação, pela Universidade Federal da Paraíba (UFPB). Bacharela em Biblioteconomia, pela UFC.

\section{Resumo}

Aborda usuários da informação no tocante ao uso do Sistema Integrado de Gestão de Atividades Acadêmicas (SIGAA) quanto às necessidades de informação e seu grau de satisfação dessa comunidade no referido sistema. $O$ objetivo foi fazer uma reflexão sobre a relação dos participantes da pesquisa com o SIGAA, e o grau de satisfação com o uso da ferramenta. Específicos: a) verificar como se realiza a prática do usuário na Arquitetura da Informação (Al), considerando o conteúdo e contexto; b) conhecer o nível de dificuldade do usuário docente relacionado à $\mathrm{Al} ; \mathrm{c}$ ) avaliar a busca e acesso pelos usuários docentes. Metodologia com uma pesquisa bibliográfica de natureza exploratória, com os docentes do Departamento de Ciências da Informação da Universidade Federal do Ceará. Instrumento de coleta de dados foi utilizado um questionário. A pesquisa observou e analisou a AI do SIGAA. Os resultados indicaram uma baixa atratividade dos grupos de funcionalidades dos docentes.

Palavras-chave: Usuários da Informação. SIGAA. Arquitetura da Informação. Necessidades de informação. Usuários docentes.

\section{The behavior of teacher users against the Information Architecture (AI) of SIGAA}

\section{Abstract}

It addresses information users regarding the use of the Integrated Management System for Academic Activities (SIGAA) regarding the information needs and their degree of satisfaction of this community in said system. The objective was to reflect on the relationship of the research participants with the SIGAA, and the degree of satisfaction with the use of the tool. Specific: a) verify how the user's practice in the information architecture is performed, considering the content and context; b) know the level of difficulty of the teaching user related to (AI); c) to evaluate the search and access by the teaching users. Methodology with a bibliographic research of an exploratory nature, with the professors of the Department of Information Sciences of the Federal University of Ceará. Data collection instrument was used a questionnaire. The research observed and analyzed the (AI) of SIGAA. The results indicated a low attractiveness of the groups of functionalities of the teachers.

Keywords: Information Users. SIGAA. Information Architecture. Information needs. Teaching users. 


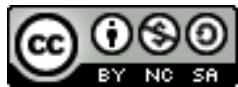

Este trabalho está licenciado com uma Licença Creative Commons - AtribuiçãoNãoComercial-Compartilhalgual 4.0

Internacional.

\section{Introdução}

Cada vez mais é perceptível e marcante a interferência das Tecnologias Digitais de Informação e de Comunicação (TDIC), como ferramenta inovadora e democrática no sistema de busca pelos seus usuários. A evolução desse fenômeno vem se tornando visível conforme lembrado por Saracevic (1996), portanto, ainda no século XX, quando considerou a explosão informacional como fenômeno marcante do século XX, caracterizado pelo crescimento exponencial da informação e de seus registros, o que tem aumentado, ainda mais, neste século XXI.

Pierozzi Jr. et al. (2003) expressa que a internet teve uma contribuição relevante e inegável tornando-se um meio de comunicação democrático, completo e inovador, jamais visto, em termos de agilidade, e em que a distância física deixou de ser obstáculo para se efetivar a comunicação.

Com o intuito de atender a tais expectativas, vale considerar que a internet trouxe uma mudança significativa no panorama da informação. Pois, de acordo com Silva e Duarte (2015), a competitividade crescente e a da atualidade fazem com que o detentor de informações na hora certa mantenha vantagem em qualquer ambiente organizacional. A sociedade da informação alterou profundamente a vida das pessoas, em relação ao processo de comunicação, por conta das ferramentas tecnológicas, como afirma Wurman (2005, p. 9):

O mundo da internet ainda está se ajustando aos novos canais de informação. As máquinas de busca ainda são rudimentares, a navegação é lenta, os caminhos para encontrar o que se procura não são fáceis, mas está surgindo uma indústria de "formatadores de informação". Em 1987, ninguém ouvia falar em arquitetura da informação. Hoje, uma pesquisa no buscador Google traz literalmente alguns milhões de resultados para a palavra-chave information architect - arquiteto de informação.

Percebe-se que na verdade hoje ainda subsiste latência em Sistemas de Recuperação da Informação (SRI) para se oferecer respostas aos usuários, no tocante à sua solicitação; por um lado, pela falha do próprio sistema e, por outro, pela falta ou insuficiência de domínio do usuário no sistema de navegação, como, também, em ele se locomover no sistema de busca, podendo não obter nem as respostas menos significativas demandadas pelos usuários. Essa busca acontece em qualquer ambiente informacional, quer seja na web ou outro meio digital, como também no universo das bibliotecas e, a exemplo, nas bibliotecas acadêmicas, nas quais, ao longo dos últimos anos tem sido oferecido um nível de independência ao usuário quanto ao acesso e uso da informação, haja vista a facilidade dessas tecnologias tanto para as bibliotecas como também para os usuários.

Todavia, mesmo que obstáculos tenham deixado de existir, quando se trata de localizar ou identificar assuntos ou termos, sua redução de acesso físico e geográfico produziu "[...] um crescimento exponencial e desequilibrado de sites na internet, onde a busca de informações e a forma de encontrá-las, tornaram-se uma missão difícil” (SILVA; DIAS, 2008, p. 119).

Estratégias para uma melhor organização dos dados inseridos nos bancos de dados dos sistemas de recuperação parece advirem do uso de técnicas de digitalização, de armazenamento e de busca, utilizando a indexação como principal ferramenta na recuperação da informação. Cardoso, (2007), em estudos no contexto da Ciência da Computação ressalta que os processos e técnicas de indexação são subáreas da Ciência da informação $(\mathrm{Cl})$, e fundamentais para, de modo sistematizado, produzir as escolhas de modelos de estratégias de busca de documentos, que atendam às expectativas dos usuários em termos de informação de valor agregado para suas buscas. 
Acreditamos que seja necessário que os profissionais envolvidos no desenvolvimento de soluções baseadas nas TDIC considerem as novas demandas dos ambientes informacionais, com novos formatos, mudanças já percebidas no comportamento e hábitos dos usuários, que passam a exigir do SRI e do profissional uma nova postura. Isto requer que esses profissionais comprometam-se a atualizar seus conhecimentos e técnicas, participar de novas capacitações e utilizar as técnicas inovadoras e instrumentos, quer sejam da Biblioteconomia, da Gestão da Informação, da Ciência da Informação e da Ciência da Computação.

Esse preocupar-se com a constante atualização profissional, deve ir além da missão fundamental de tornar conhecidos, utilizados pelos usuários e praticados no SRI, conceitos de aprimoramento de interfaces pelo estudo das qualidades ergonômicas, como o estudo de Bastien e Scapin (1993), ou Nielsen e Jakob (2000). A desconsideração da necessidade do constante aprendizado profissional, e da não observância da epistemologia relacionada à ergonomia pode introduzir sérios riscos de frustração ao potencial usuário da informação. Sobre essa frustração nos falam Morville e Rosenfeld (2006) em que sugerem que a incapacidade de encontrar uma informação é um dos fatores que mais frustram os usuários.

A Arquitetura da Informação (AI), para os SRI, surge no cenário da $\mathrm{Cl}$ e da Gestão da Informação, com princípios, métodos e técnicas, tendo a função de prover arcabouço tecnológico para projetar a estrutura de como se expressa a informação de qualquer natureza. O propósito principal é provocar interação entre usuário e o sistema de informação de forma amigável, inteligível e com grandes chances de responder com êxito às buscas de informação dos usuários. Sobre a $\mathrm{Al}$, argumentaremos com mais detalhes à frente. Esta área técnica da Ciência da Informação vem-se consolidando, com base em etapas de processamento técnico de indexação advindos das representações temáticas estudadas na Biblioteconomia, e as taxonomias e vocabulários controlados, auxiliando na elaboração e tratamento de conteúdos e interface, mais focados nas pesquisas da $\mathrm{Cl}$ e da Gestão da informação.

Um possível entendimento que decorre dessa argumentação é que nos ambientes nos quais os sistemas de informação são um ponto central, isto é, nos quais o atendimento do potencial usuário da informação é o ponto mais importante, devam ser desenvolvidos sistemas e processos com base nas abordagens centradas nos usuários, por entender-se que os mesmos são os agentes nos ambientes que definem os componentes de acesso, busca e usos da informação, para uma perfeita e adequada recuperação da própria informação. Esse entendimento é necessário para evitar-se o problema apontado por Xu, 1999 apud CARDOSO, (2007, p.4), que nos diz que "Um problema fundamental em recuperação de informação é que os autores nem sempre usam as mesmas palavras que os usuários para descrever o mesmo conceito" (XU, 1999 apud CARDOSO, 2007, p.4).

Justifica-se ainda mais a preocupação com a Al quando consideramos que se pode facilmente perceber um movimento favorável à utilização de microcomputadores, e demais equipamentos móveis tais como o smartphone, o tablet, etc. O uso de tais equipamentos vem-se expandindo continuamente, até em razão da baixa dos custos, os quais favorecem a que muitas pessoas tenham acesso à informação digital, porquanto ela vem facilitando para todos; de modo que grande parte da sociedade possa ter acessibilidade à internet, permitindo, portanto, que o seu uso seja cada vez mais amplo e, consequentemente, com pouca restrição para sua utilização por todos e qualquer um.

Se por um lado observamos esse movimento ascendente de uso massificado dos equipamentos com capacidade de acesso à informação, por seu turno, a informação em permanente estágio de evolução, enquanto matéria prima, ela precede à comunicação, à tecnologia, à ação e ao conhecimento (ILHARCO, 2003). O qual conceitua o conhecimento:

O conhecimento científico e o desenvolvimento tecnológico mudou tanto nas duas últimas décadas, que não só mudou o mundo como o transformou em algo de entendimento impossível face à quantidade, à complexidade da constante e progressiva fragmentação e integração de uma infinita informação, matéria, energia e tempo (ILHARCO, 2003, p.10).

Então, as rotinas de outrora, as práticas, as possibilidades se alteraram, se colocando os desafios que estão por vir, além dos já existentes, para serem enfrentados no século XXI.

Obviamente uma dessas alterações toma nome e corpo nos processos relativos ao planejamento da própria Al. Reforçandose esse entendimento nas palavras de Wurman, o qual nos diz que "os arquitetos de informação eficazes tornam o complexo 
claro e consequentemente qualifica o acesso, eles tornam a informação inteligível para outros seres humanos" (WURMAN, 2005).

Para isso, torna-se necessário, também, a capacitação de pessoas para assumir tal desafio.

"Para que os processos organizacionais se efetivem, é necessário que existam competentes indivíduos nos seus quadros. 0 conceito de competência está originalmente centrado no indivíduo, ou, pelo menos, na capacidade de que algum indivíduo possua, ou possa adquirir tal predicado" (ESPANTOSO, 2010, p.1).

Quando há um trabalho feito por profissionais que levam em primeira instância o pensamento e a ação voltada para o usuário, em refletir quem é esse usuário, como ele quer encontrar a informação, e como se comporta no sistema de busca, além de elaborar as inúmeras questões possíveis, deve-se pôr-se no lugar dele, ou seja, o usuário.

Assim, a não informação ou a desinformação também acontece, em alguns casos, quando o sistema não consegue esclarecer ou responder o que se quer, conforme explana Wurman, (2005, p.14): "A ansiedade de informação é causada pela distância cada vez maior entre o que compreendemos e o que achamos que deveríamos compreender. É o buraco negro existente entre os dados e o conhecimento, que aparece quando a informação não diz o que queremos saber".

Com isso, dentro deste contexto, percebe-se que a tecnologia, quando se consideram os equipamentos, ou quando se considera a forma como organizamos a informação no espaço digital, materializada pela Al utilizada, deve ser empregada e moldada de maneira a atender as necessidades do potencial usuário da informação. Àqueles envolvidos nos trabalhos da Al, sejam em ambiente web ou não, devem integrar-se ao usuário no momento do planejamento desses recursos. Dessa integração se pode esperar SRIs que permitam um melhor conforto aos usuários e também àqueles que dele dependem para a gestão de interesses institucionais.

Um exemplo de SRI que pode ser citado dentro do contexto apresentado é o Sistema Integrado de Gestão de Atividades Acadêmicas (SIGAA), em sua versão utilizada na Universidade Federal do Ceará (UFC, 2017). O SIGAA foi adotado pela UFC e tem por missão atender às necessidades informacionais e administrativas dos docentes, discentes e servidores técnicoadministrativos de seus quadros. Devido a sua relevância no contexto em que se insere na vida acadêmica e profissional dos envolvidos, lançamos um olhar sobre a forma como os usuários interagem com o SIGAA, na materialização de sua AI, desdobrando esse olhar no enfoque particular de suas funcionalidades relativas às necessidades dos docentes da UFC, retratados no recorte de dados que compreende a pesquisa realizada.

Delineamos como objetivos específicos o seguinte: a) verificar como se realiza a prática do usuário na $\mathrm{Al}$, considerando o conteúdo e contexto; b) conhecer o nível de dificuldade do usuário docente relacionado a arquitetura da informação; c) avaliar o sistema em função da busca e acesso pelos usuários docentes.

\subsection{Arquitetura da Informação e a Usabilidade}

O termo Al foi criado pelo designer gráfico Richard Saul Wurman em 1975, (Wurman, 2005), e foi consolidado em 1976, na Conferência Nacional do AIA (American Institute of Architect). Parece ser claro que Wurman tem como objetivo principal tornar a informação compreensível.

O Instituto de Arquitetura de informação, enquanto organização internacional no assunto, se responsabiliza em promover o avanço da prática da Al, definindo como a arte e a ciência de organizar e catalogar websites, intranets, comunidades online e software, a fim de garantir a sua usabilidade (IAA, 2010).

Os estudos de usabilidade em recursos na internet (páginas web) se tornam necessários até por que se faz fundamental analisar alguns aspectos concernentes à interação homem-computador (IHC), e a identificar os problemas de natureza diversa, de modo a que se possam corrigir as falhas detectadas, em função da satisfação dos usuários. 
Dentro dessa concepção e objetivo, a construção do design deve ser pensada a partir da fidelidade que o sistema deve ter em corresponder às reais expectativas e interesses dos usuários. Como diz Ferreira e Pithan (2005, p. 645):

Os resultados, apresentados na literatura, de estudos de avaliações sobre a real utilização de inúmeros sistemas de informação (englobando-se base de dados, bibliotecas digitais, websites, portais, dentre outros) vêm mostrando a dificuldade que os projetistas desses sistemas estão enfrentando para efetivamente criar produtos e serviços que possam fidelizar, captar e satisfazer as expectativas e interesses de seus usuários finais.

A estrutura planejada da Al tem por finalidade possibilitar o desenvolvimento de um SRI confiável que garanta a recuperação da informação, a disseminação em função das necessidades informacionais dos usuários. "A arquitetura da informação foi inicialmente aplicada em mídias impressas (mapas, guias...), porém, tem-se desenvolvido na área de criação e organização de websites" (REIS, 2006 apud SILVA; DIAS, 2008, p. 2).

Peter Morville e Louis Rosenfeld, na terceira edição de seu livro: Information Architecture for the world wide web: design largescale, também conhecido como 'urso polar' (2006, p. 4) (segundo, tradução nossa), como autoridades e estudiosos na área, registram algumas definições sobre $\mathrm{Al}$.

1. O design estrutural de ambientes informacionais compartilhados; 2. A combinação de sistemas de organização, rotulação, navegação e busca, dentro de websites e intranets; 3. A arte e ciência de formatar produtos de informação e experiência para apoiar a usabilidade e encontrabilidade; 4. Uma disciplina emergente e comunidade de prática focada nos princípios de design e arquitetura para o ambiente digital.

Podemos traduzir esses conceitos no trabalho prático do profissional que é responsável, exemplarmente, pelo planejamento de um site, que deverá ter na apresentação toda a imagem do que se quer projetar. Iniciando com o processo da organização do conhecimento, e imaginando qual seria a melhor maneira de se colocar a informação: as taxonomias por critérios préestabelecidos (por exemplo: alfabética, cronológica ou por outra escolha) entre outras recomendações.

Em se tratando de sistema que expõe a ordem dessas terminologias, devem ser definidos no espaço informacional os rótulos a serem seguidos, como também a forma de navegar (global, local e contextual).

Quando o usuário faz sua busca, a funcionalidade é o principal requisito, sendo inerente à necessidade de informação manifestada por vezes através de uma expressão de busca, ou pelo acionamento de alguma funcionalidade de processamento do SRI.

Dentre os muitos profissionais que podem (e se envolvem) com o planejamento de arquiteturas da informação, citamos o bibliotecário, o qual deve expressar conhecimentos que vão além do que foi visto diretamente na sua formação profissional, evidenciando também (mas não se limitando) àqueles saberes de natureza tecnológica aplicada em linguagens de marcação para estruturação de documentos tais como o XML e o HTML, como também em elaborados esquemas de meta dados e nos programas aplicativos.

Os autores até aqui citados, tomados como base teórica para este trabalho, estão focando de maneira enfática o como praticar a Al no mundo real, sobressaindo-se, com referência à prática de projeto da $\mathrm{Al}$, e chamando a atenção para três termos relevantes e fundamentais: usuários, contexto e conteúdo.

Vejamos representados esses três pilares da arquitetura da informação na visão de Peter Morville e Louis Rosenfeld, retratados na Figura 1 
Figura 1 - Pilares da Arquitetura da Informação

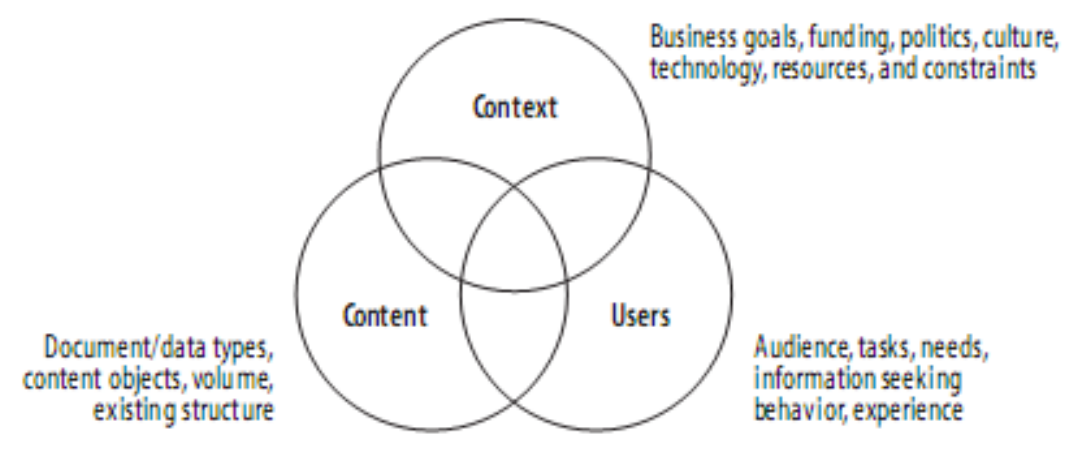

Fonte: Peter Morville e Louis Rosenfeld (2006).

Na Figura 1, os autores consideram o ciclo, por esses termos constituídos, de natureza interdependente, dentro de um complexo chamado ecologia da informação. Advertem, então, sobre a necessidade de os indivíduos se cientificarem quanto à natureza e volume do conteúdo de informação hoje existente e como isso poderá mudar daqui a algum tempo, havendo a conveniência de se aprender sobre as necessidades e sobre o comportamento de busca de informação, que é a grande ênfase: "Um bom arquiteto da informação sabe como começar o trabalho e, ao mesmo tempo, ter algum divertimento ao longo do caminho" (MORVILLE; ROSENFELD, 2006, p. 25)

Com essa especificidade, inerente ao trabalho do arquiteto da informação, Bentes Pinto, Tabosa e Vidotti, (2011, p. 3), se expressam, ao articular esses termos acima citadas, (usuários, contexto e conteúdo): "Acrescentamos a esses aspectos mais dois que consideramos de fundamental importância: o feedback e a avaliação, pois a Arquitetura da Informação, em nosso entendimento, configura-se como um processo de comunicação.

Tais aspectos devem ser incluídos na Al, enquanto processo de comunicação, o que, evidentemente, conduz ao que é fundamental em qualquer trabalho, quanto a avaliação a ser realizada, sobre sua pertinência, fundamental em qualquer atividade de planejamento, de modo que, haja o atendimento a indagações feitas pelos utilizadores da informação.

Quanto a aplicabilidade da Al, merece ser contemplado o pensamento a seguir exposto:

A Arquitetura da Informação aplicada na criação de ambientes informais digitais da web conduz melhor o usuário às informações desejadas e torna o acesso a elas mais eficaz e preciso, com o planejamento e a organização virtual da informação digital que facilita a construção e navegação neste sistema hipertextual (BENTES PINTO; TABOSA; VIDOTTI, 2011, p. 2636).

Que as pessoas envolvidas no trabalho de Al de maneira permanente e, em alguns casos, aquelas que nunca ouviram falar em Al, possam ser treinadas e se tornem conhecedoras de pesquisas sobre as necessidades de informação dos usuários, em ambientes digitais, para evitar excesso de concentração de informação no sistema, sem corresponder ao interesse desses usuários. Segue o que diz Agner e Silva (2003, p. 6).

A Arquitetura da informação precisa ser estudada hoje devido ao aumento da população de usuários, das necessidades organizacionais e da compreensão do comportamento humano e seus aspectos cognitivos. A confusão entre transmitir simplesmente dados e criar mensagens com significado pode ter tido sua origem na atenção demasiada dada aos computadores e na pouca atenção dada aos usuários.

Dentre as atuações do arquiteto da informação, convém indicar como indispensável que ele possua domínio das tecnologias, acompanhando todas as inovações e as use com criatividade e arte e, portanto, que facilite a organização, navegação, e, evidentemente, a rotulação dos sites de apoio, a encontrabilidade e usabilidade. Diz Espantoso (2010): O arquiteto da informação por atuar em um meio onde existe forte influência da tecnologia deve estar atento às novas soluções emergentes. 
Neste sentido, seu espírito de empreendedor e de pesquisador é requisitado naturalmente no desempenho de atividades, principalmente na busca por respostas que desvendem os desafios de construções de arquiteturas de informação em ambientes organizacionais.

Esses ambientes informacionais devem-se tornar atrativos, organizados, com sistema de busca coerente para o usuário.

A proliferação da informação vem sendo visível na área da $\mathrm{Cl}$, o que interfere diretamente no trabalho do arquiteto da informação, quando Nielsen, apud Ferreira; Pithan, (2005, p. 645), diz que a usabilidade tornou-se uma questão de sobrevivência na economia da internet "existe uma abundância de sites disponíveis, [portanto] sair é a primeira medida de defesa quando os usuários encontram dificuldades".

Diante dessas dificuldades, percebe-se que elas deverão estar relacionadas ao sistema de organização, de navegação, de busca e de rotulagem, bem definidos por Morville; Rosenfeld (2006), dado o grande número de opções disponíveis, a arquitetura de informação pode determinar a permanência ou abandono dos sistemas virtuais pelos usuários.

No intuito de facilitar o entendimento do usuário no acesso ao site, a primeira iniciativa do arquiteto da informação é a tomada de decisão do que e como organizar a informação em todo o site, considerando a relevância do estudo do uso do sistema, por aqueles usuários que de fato utilizam o sistema, como também por outros usuários, para conhecer as reais necessidades deles. Dai, a possibilidade de evitar que os internautas tenham dificuldade de realizar suas tarefas.

Assim, no estudo de necessidades de informação dos usuários, acredita-se que esse usuário saiba o que quer, e que também saiba conduzir a sua busca, expressando o que deseja e o que necessita, por meio dos estudos feitos a partir de modelos de formulários.

Seguindo o raciocínio de Costa (2016, p 89): "[...] observamos que merecem evidência os termos - usos, necessidades e comportamentos, por estarem completamente interligados. Uso da informação tem associação direta com o significado da informação, aquilo que ela acrescenta, que soma, e que tem valor para o usuário".

A partir da busca e uso da informação, o usuário associa o valor que a mesma tem, em função de seu significado.

Por outro lado, quando se lança um recurso informacional na web ou não, se deve lembrar que primeiro foco, com relação ao usuário, é no sentido de acolhê-lo, facilitando-lhe a busca e apresentando as melhores possibilidades na sua ordem de interesses. A partir dai, "A intenção de todo site é impressionar o internauta, mas não se pode esquecer que o usuário vai precisar ler e encontrar certos elementos no site, navegar e ser induzido a clicar" (SILVA; DIAS, 2008).

A responsabilidade da Al é traduzida na definição de uma estrutura, delineando a sua organização, a navegação, a rotulagem e o sistema de busca do usuário. O que naturalmente as outras partes se apoiarão na organização dessas informações.

Ainda, tratando-se da importância e necessidade de estudos de usabilidade, é recomendável que se faça avaliação do site, em função de verificar os ajustes recomendáveis a serem feitos no sistema. Assim, como afirmam Ferreira; Pitfhan, (2005, p.653): "Mesmo com a resolução dos problemas, outros estudos de usabilidade são recomendados, para que problemas não percebidos nestes testes, possam ser identificados futuramente, ou até mesmo, problemas gerados pelas alterações e reformulações sejam detectados antes do lançamento do site".

Por sua vez, asseguram as autoras que a usabilidade, conforme Nielsen, 2003, apud Ferreira; Pithan, (2005) é um atributo de qualidade que serve para avaliar a facilidade do uso de uma interface, a fim de possibilitar aos usuários o desenvolvimento de tarefas de maneira clara e útil, podendo ser vista sob as seguintes variáveis: aprendizagem, eficiência, memorização, erros e satisfação pelos usuários.

No estudo da usabilidade sugere-se observar essa sequência, de modo a obter os resultados almejados, identificando problemas para possíveis ajustes ou até mudança do design apresentado no site. "Os princípios de usabilidade são responsáveis pela interação do usuário com o website, de maneira que consiga recuperar e acessar as informações sem obstáculos" (FERREIRA; VECHIATO; VIDOTTI, 2008, p. 121). Ratificam esse entendimento Silva e Dias (2008), no qual é 
apresentada uma avaliação do site da Biblioteca Virtual da Saúde (BVS), biblioteca que opera com milhões de acessos às fontes de informações. Eles chamam à atenção relativamente aos desafios postos, no tocante a navegação para dar maior mobilidade aos seus usuários; com rótulos inteligíveis; e, uma busca lógica com acesso à informação almejada. Corroboram esse entendimento de Souza e Tabosa (2014) que nos dizem que a "Acessibilidade na web é permitir que qualquer pessoa, independentemente da tecnologia que utilize, possa navegar sem restrições, podendo interagir com o site e obter a informação que busca".

Pode-se perceber que a Al é a característica abstrata que se encontra ao acessar um recurso na web, e que a usabilidade é uma das ferramentas fundamentais à boa materialização de um projeto de Al. Ambas estão relacionadas de maneira indissolúvel.

\subsection{Sistema de Recuperaçao da Informação}

As TDIC são as principais ferramentas utilizadas nos SRI com a finalidade de facilitar as buscas dos usuários nos ambientes informacionais. No entendimento de Morville e Rosenfeld (2006), temos que explicitar tudo da melhor maneira nos SRI, utilizando preferencialmente a terminologia compreendida pelo usuário, definindo as perguntas que o usuário deve fazer e o que o sistema deve responder. Para Vidotti e Sanches (2004), o sistema de busca auxilia na localização e no acesso às informações, observando como os usuários fazem tais buscas. E para a recuperação dessas informações, evidentemente fazse necessário que se tenha uma representação descritiva e temática adequada aos conteúdos.

Quando o usuário se utiliza do sistema de busca no portal de uma instituição acadêmica, por exemplo, é importante que a apresentação da página principal tenha um projeto organizado, que permita dar conhecimento sobre como navegar da melhor forma, e que, a partir da organização da página, o usuário possa tomar conhecimento, para efetivar um sistema de busca dentro do que é desejado, isto é, com plena obtenção do sucesso.

Sabe-se que, no sistema de busca, as pessoas procuram, às vezes, os mesmos assuntos, porém, o fazem com termos diferentes. Com isso, o arquiteto da informação, responsável por apresentar o projeto de organização da página institucional, deve ter em mente a organização, o repensar acerca do quantitativo de informações sobre determinado assunto para evitar problemas, eliminando a dubiedade para os usuários, como também evitando que ele obtenha resultados pouco relevantes.

Os arquitetos da informação, com suas habilidades artísticas e criatividade, devem apresentar várias opções de navegação, assim oferecerão oportunidades maiores de sucesso ao usuário, no momento de busca por informação.

Evidentemente, na busca procedida pelo usuário, está implícito que a primeira iniciativa está no reconhecimento das fontes a serem pesquisadas, que poderão servir de ponto de partida. Ao mesmo tempo, devem-se aproveitar as sugestões também feitas por aquelas fontes. No momento de agrupar as informações relacionadas ao tema, deve-se também filtrá-las, selecionando as principais fontes de informação, e, posteriormente, verificando a consistência dessas fontes e a veracidade das mesmas, para fins de estrutura do texto.

Para que essa busca se torne mais evidente e tenha resposta favorável para o usuário, existem vários modelos comportamentais que podem fornecer elementos a serem considerados para a melhoria dos sistemas, dentre eles, o de Ellis (1989), que se propõe como modelo, com atividades genéricas de busca:

a) iniciar, com a identificação de fontes, como ponto de partida;

b) utilizar de outras fontes, sugeridas pelas fontes iniciais;

c) agrupar informações relacionadas ao tema;

d) filtrar e selecionar fontes;

e) acompanhar com regularidade o progresso da área;

f) explorar sistematicamente uma ou mais fontes;

g) revisar e checar para evitar erros; 
h) finalizar, verificando a literatura, após a conclusão de uma pesquisa.

Nota-se que a sequência desse modelo proposto segue percurso semelhante à de qualquer pesquisa feita em ambientes da web, ou digitais.

No momento de dar início ao planejamento, enfatiza-se como primeiro passo a ser dado pelo arquiteto da informação o de conhecer as necessidades de informação. De fato, tal providência é fundamental para se alcançar a necessária interface de interação entre o usuário e o sistema.

Todavia, ainda que se considerem todos os elementos expostos até aqui, existem fatores técnicos que interferem no desempenho efetivo do SRI. Esses fatores referem-se à forma como as informações são representadas nos sistemas computacionais e como se comporta o mecanismo envolvido na seleção e recuperação dos dados. Normalmente esses fatores são chamados de modelos de recuperação.

Um modelo de recuperação amplamente difundido é o modelo booleano, trata-se de um modelo de recuperação desenvolvido com base na álgebra de Boole. Quando um potencial usuário fornece uma expressão de busca ao sistema, este processará uma comparação que consiste em verificar se a expressão de busca está contida ou não no documento. Há variações quanto a esse comportamento pela inclusão de operadores lógicos previstos na álgebra de Boole, tais quais os operadores E (AND), ou (OR) e não (NOT).

O modelo de Boole está relacionado ao modelo Fuzzy (SHAW; SIMÕES, 1999) no qual o conceito de pertinência envolvido nos operadores lógicos é ampliado para uma resposta para além do "está contido" ou "não está contido". O sistema passa a considerar valores de pertinência do conjunto que compõe a resposta em relação à expressão de busca usada pelo usuário. Normalmente esses valores correspondem a faixa entre o 0 (zero) e 01 (um).

Outro modelo refere-se ao probabilístico, o qual opera a partir de sucessivos refinamentos entre a expressão de busca e o resultado obtido. O resultado inicial da consulta pode ser produzido com qualquer modelo de recuperação, sendo posteriormente submetido ao usuário, o qual por sua vez, indica quais documentos referenciados no resultado tem maior relevância para a sua pesquisa (MANNING; RAGHAVAN; SCHUTZE, 2009). Esse processo continua até que o usuário esteja satisfeito ou não existam mais refinamentos possíveis.

Há também o modelo vetorial (SALTON; YANG, 1973) para o qual utiliza-se o conceito de atribuição de um valor de relevância a cada token do documento. Um token é uma unidade mínima considerada na abordagem, geralmente é uma palavra, ou uma frase. A partir do conjunto de valores relativos a todos os tokens de um documento, cria-se um vetor que o representa. Quando o usuário fornece uma expressão de busca essa expressão também é convertida em um conjunto de valores que associa cada token da expressão a valores de relevância. A resposta desse tipo de sistema fornece uma relação classificada do ponto de vista da maior até a menor relevância da resposta obtida.

Para cada tipo de modelo de recuperação haverá um comportamento do sistema, e o desempenho final do SRI depende diretamente dessa escolha.

\subsection{Necessidades de Informação e o Usuário como Foco}

Para pensar a elaboração do planejamento desses ambientes é indispensável à tomada de decisão do que se quer projetar, a partir do entendimento do que e como o usuário busca e com que intenção a informação tem relevância para ele. Então, a partir do uso, o que nem sempre poderá apresentar resultado satisfatório ao usuário, sendo mais relevante o significado que essa busca representou ou representa para ele.

Sabe-se que o usuário com sua percepção aguçada conforme o pensamento de Costa e Almeida Júnior (2012), afirma: "Quanto à percepção do usuário, ela é guiada pelo valor e pela utilidade que a informação tem: dependerá do significado dado por ele e pela situação em que se encontram as lacunas do seu conhecimento" (COSTA; ALMEIDA JÚNIOR, 2012, p. 60). 
Entendemos que sempre deverá haver estudo que relacione o conteúdo, (explicitando o que será informado); os usuários (as necessidades de informação) e o contexto, fazendo com que o olhar da Al seja voltado para o usuário/cliente, buscando a qualidade e a melhoria do sistema.

Em sintonia com o que diz Costa; Silva; Ramalho (2009, p. 11) discorre acerca do conhecimento das necessidades de informação, ao expressar:

Conhecer as necessidades de informação dos usuários significa conhecer fatos da sua vida cotidiana e, também, entender o verdadeiro significado que a informação tem para esses indivíduos. Por outro lado, o entendimento das necessidades de informação dos usuários habilita o profissional da informação a oferecer, para esses usuários, serviços de informação mais eficientes e eficazes, em relação ao atendimento de suas necessidades.

Pensando na era atual não se justifica projetar sistema em ambientes digitais, por exemplo, sem considerar uma série de fatores, o mais essencial deles ou prioritário é o conhecimento para quem é voltado o sistema. Como diz Fischer; Araújo, (2010, p.5): "O foco no usuário representa a utilização de técnicas e métodos que busquem trazer os usuários para o processo de design, a fim de se criar produtos, que além de possuir uma boa usabilidade, sejam adequadas às reais necessidades das pessoas".

Os designers, no caso, devem ter a sensibilidade em saber o tipo de público para o qual o site deve ser projetado a fim de entender as diferentes especificidades de cada pessoa, utilizando termos próprios a cada área de interesse. Nesse aspecto, dificilmente a Ciência da Informação não estaria envolvida com a Al, juntamente com outras áreas participantes como mostra a figura constando das disciplinas que contribuem para a AI. (DILLON, 2000, apud Fischer; Araújo, 2010).

Figura 2 - Disciplinas que contribuem para a arquitetura da informação

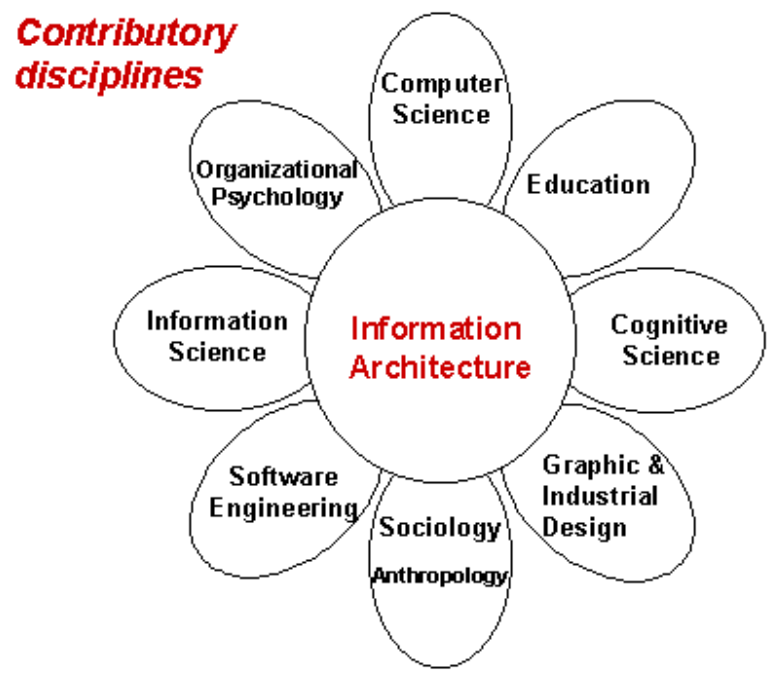

Fonte: Dillon (2000) (http://goo.gl/lyrL).

Assim, numa abordagem que se pode dizer inclusiva e compartilhada ou social, no mínimo, podemos perceber que diferentes profissionais projetam a Al como expediente, espaço, meio, mecanismo, instrumento ou oportunidade facilitadora de ordenamento e organização das informações, no objetivo e função do seu acesso, uso, arquivamento e recuperação.

Sendo então nessa abordagem, eleitos o usuário e sua necessidade informacional como foco do trabalho, acreditamos que deva ser o objetivo de qualquer SRI agregar valor à informação, adequando-a ao seu potencial usuário, em uma visão alinhada ao que nos diz De Souza (2015, p. 162):

O sentido que se deseja evidenciar para a informação solidária refere-se mais à adaptação dessa informação ao usuário, de forma dinâmica em termos de organização e apresentação, aproximando-se de arquiteturas da informação personalizadas ao sujeito envolvido. Vislumbra-se uma informação solidária, uma informação amigável. 
$\mathrm{Al}$, atendendo como aparato às necessidades de informação, consegue auxiliar aos usuários a aprofundar em suas áreas de estudo e fazer várias profissões transitarem, em apoio às respostas requeridas. Pois, de acordo com Costa (2016) vale salientar que o que caracteriza a necessidade de informação é, entre outros, o aspecto cognitivo que determina a razão pela qual se tem necessidade de informação, como se envolve nesse processo e como há de se fazer a sua busca. De fato, cade caracterizar porque a pessoa procura informação. Obviamente as razões se tornam pouco evidentes ou insuficientemente claras, na maioria das vezes e, portanto, pouco explícitas, por serem eminentemente subjetivas, até pelo desconhecimento ou conhecimento insuficiente, ou por falta de esclarecimento ou de domínio, em alguma questão, em especial, as de natureza científica.

O ser humano, como ser social, necessita da participação e integração na sociedade, e a informação leva a tomadas de decisão do indivíduo, favorecendo a que o uso da informação lhes traga significado.

Cada profissional deixa impresso o caráter peculiar de suas visões ou approach específicos em benefício das diferentes ciências e de maneira especial àquelas mais focadas no trato da informação.

Por isso, profissionais da eletrônica, informática, engenharia, sociologia, comunicação, biblioteconomia, ciência da informação e ciência da computação direcionam ou redirecionam todo o empenho no escopo de oferecer suporte aos demandantes de informação em acessá-la nos novos ambientes e com novas técnicas.

Por conseguinte, a arquitetura daqueles profissionais torna-se um modo de organizar o espaço e o aspecto de apresentação mais funcional e mais razoável ou inteligente da informação, o que vai se constituir numa contribuição coletiva de agentes que integram a Ciência que, aliás, nunca poderá ser considerada como singular ou hermética.

Obviamente a Ciência da Informação tem a oportunidade de se debruçar sobre a multiplicidade de suas áreas de trabalho e intervenção, captando todos aqueles ingredientes da Ciência e Arte que professam, verificando mais ainda a apropriação legítima que possuem em contribuir com as novas e inovadoras ferramentas, dentro do seu próprio espectro funcional ou profissional.

\subsection{Sistema Integrado de Gestão de Atividades Acadêmicas (SIGAA)}

Neste texto elegemos o Sistema Integrado de Gestão de Atividades Acadêmicas. Esse SRI é utilizado em várias instituições de ensino superior, dentre elas as seguintes universidades federais: do Ceará, do Rio Grande do Norte; do Piauí; de Sergipe; do Maranhão; de Alagoas, dentre outras.

O SIGAA informatiza os procedimentos da área acadêmica através dos módulos de: graduação, pós-graduação (stricto e lato sensu), ensino técnico, ensino médio e infantil, submissão e controle de projetos e bolsistas de pesquisa, submissão e controle de ações de extensão, submissão e controle dos projetos de ensino (monitoria e inovações), registro e relatórios da produção acadêmica dos docentes, atividades de ensino a distância e um ambiente virtual de aprendizado denominado Turma Virtual. Da mesma maneira do SIPAC também disponibiliza portais específicos para: reitor, professores, alunos, tutores de ensino a distância, coordenadores de cursos de graduação e de pós-graduação e de comissões de avaliação (institucional e de docente).

Na página inicial do modulo acadêmico apresenta uma operação que tem como finalidade possibilitar que o discente recém integrado à Instituição, realize o cadastro de usuário no SIGAA. Esse procedimento tem a função de realizar o cadastro que será necessário para que o discente possa ter vinculo ativo com a Instituição. Não será permitido ter mais de um usuário relacionado com um mesmo número de matrícula. O processo somente será validado se as informações fornecidas forem consonantes com os dados informados no processo seletivo. Essas informações são fundamentais para o docente utilizar o SIGAA, principalmente o modulo acadêmico.

Ainda no modulo acadêmico o SIGAA permite que o docente possa atualizar sua foto e informações do perfil que foram previamente cadastradas no sistema, assim, como também permite visualizar os dados pessoais. 
O módulo ensino Graduação de acordo com o criador do SIGAA: Universidade Federal do Rio Grande do Norte (UFRN) tem o intuito de atender as demandas da Pró Reitoria de Graduação (PROGRAD), dos departamentos, dos cursos de graduação e de pós-graduação, dos docentes e discentes, procedimento também adotado pela Universidade Federal do Ceará (UFC), campo de pesquisa desse artigo.

Esse mesmo módulo de ensino tem como objetivo auxiliar às atividades intrínsecas a Graduação sob todos os aspectos. O aluno regular da graduação ingressa na Universidade através das possíveis formas de entrada na instituição, tais como: Exame Nacional do Ensino Médio (ENEM), transferência e portador de diploma de outras Instituições de Ensino Superior (IES) que possui matrícula e que se encontra vinculado a um curso regular. Esta modalidade de aluno constitui a maior parte do corpo discente da UFC.

Portanto é por intermédio deste sistema que os docentes podem ter acesso aos módulos disponibilizados no que se refere à área acadêmica. Como exemplo: o cronograma elaborado por cada docente a fim de ser disponibilizado ao corpo discente para possibilitar a interação com a turma, além do acesso a documentos em que comprove o vínculo entre a comunidade universitária, em especial docente e discente.

Assim, os docentes podem usar o sistema dentro da sala de aula e fora dela, mas não podemos deixar de falar que isso nem sempre é real, pois acontecem vários eventos que podem prejudicar essa prática.

Figura 3 - Interface principal do SIGAA - Versão UFC

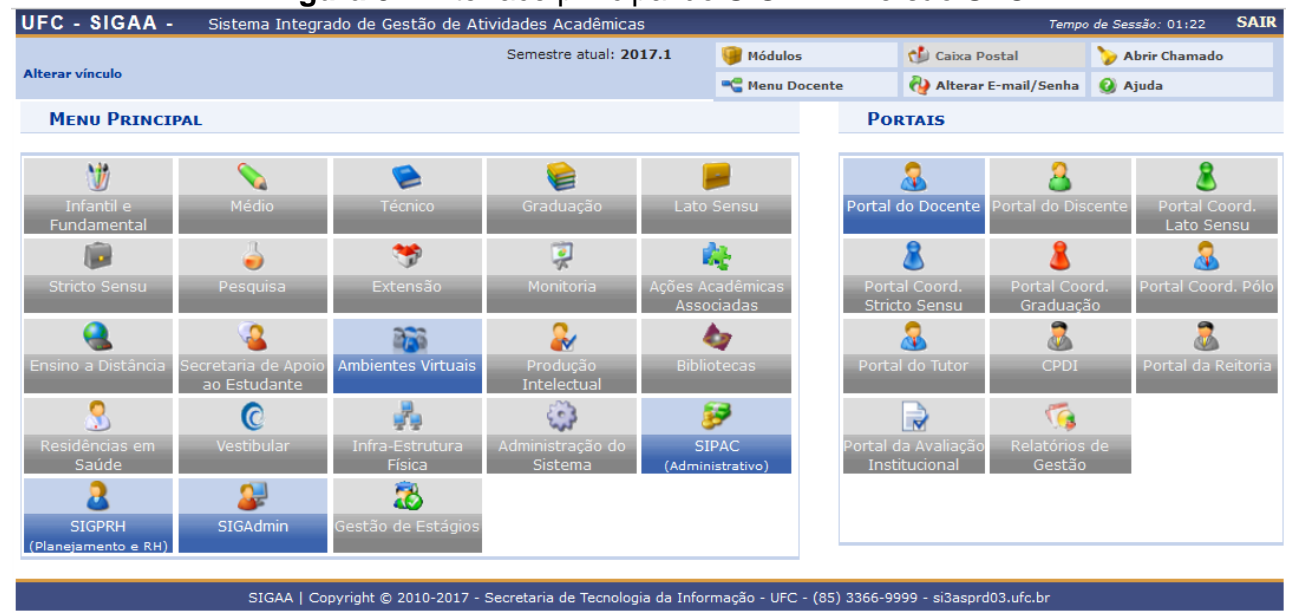

Fonte: SIGAA UFC (2017)

Para a realização da pesquisa pretendida no trabalho elegeu-se a versão administrada pela Universidade Federal do Ceará como o corpus desta pesquisa.

Como ferramenta o SIGAA apresenta diversos módulos, os quais proveem funcionalidades distintas, distribuídos na interface central do SRI como se vê na Figura 3 acima.

\section{Materiais e Métodos}

A pesquisa foi realizada no recorte cronológico de fevereiro a abril de 2017. Os trabalhos tiveram início a partir de uma pesquisa bibliográfica realizada no sentido de se conhecerem os autores que forneceram o suporte teórico para este trabalho. Em seguida foi realizada uma pesquisa exploratória necessária para se conhecerem as impressões e níveis de satisfação dos usuários com a ferramenta SIGAA.

O instrumento de coleta de dados escolhido para ser utilizado na pesquisa, foi o questionário, composto por 16 questões, objetivas, e com oportunidade de se auto manifestarem ou de se expressarem com outras formas de entendimento, se iniciando como a frequência do uso e das ferramentas disponíveis do SIGAA. 
Nessas ferramentas se encontram alternativas de ensino, de produção intelectual e ambientes virtuais, além de outros. Também foram indagados, acerca de problemas detectados de difícil acesso, ou de demora à efetivação de registros de conteúdos diferenciados, incluindo o da bibliografia.

Contemplamos também, por meio do questionário, a utilização com sucesso ou não, no caso de Abrir Chamada, o que se considerou item comum na utilização pelos docentes, de alguma ocorrência em situação de ajuda.

Assim, descobriríamos a frequência de uso, e do que não é utilizado pelos docentes, a fim de conhecermos por meio da avaliação docente, a interface com o Sistema. O instrumento também ofereceu opções que pudessem favorecer a segurança do docente nas respostas.

Sabemos que temos itens, por exemplo, no ensino, que são mais utilizados, pelos docentes, principalmente aqueles que dizem respeito às necessidades habituais e de fácil acesso ligados às disciplinas.

Consideramos também ser de muita relevância as informações exibidas em determinadas posições no site e se essas auxiliem a uma utilização com mais qualidade ao trabalho docente, a fim de instruírem a melhoria e qualidade do ensino.

Desse modo tal instrumento foi construído no que aguardamos o tempo necessário dos docentes nos responderem como também as sugestões enviadas.

A pesquisa envolveu o Corpo Docente do Departamento de Ciências da UFC, composto por 19 docentes, sendo que destes, 15 responderam as questões apresentadas.

\section{Análise e Discussões}

Podemos perceber que os docentes, no recorte da pesquisa, em sua maioria não fazem uso diário do SIGAA, aproximadamente $53 \%$, ao somarmos todas as respostas, exceto o "uso diário" que isolado aparece com $46,7 \%$. A maioria $73,3 \%$, como se vê acessa o SIGAA para utilizar ferramentas relativas ao ensino. Esse mesmo grupo indica que os usuários percebem vários tipos de problemas, que corrobora a alta frequência com que os participantes da pesquisa solicitaram auxílio através da funcionalidade "abrir chamado". Desses participantes apenas $26,7 \%$, nunca solicitaram auxílio, o que claramente indica que há um conjunto relevante de problemas percebidos pela maioria dos usuários que participaram da pesquisa. Observamos ainda que $26,7 \%$ afirmam que utilizaram o recurso de auxílio, mas não obtiveram sucesso.

Como diz Ferreira e Pithan (2005, p. 645):

Os resultados, apresentados na literatura, de estudos de avaliações sobre a real utilização de inúmeros sistemas de informação (englobando-se base de dados, bibliotecas digitais, websites, portais, dentre outros) vêm mostrando a dificuldade que os projetistas desses sistemas estão enfrentando para efetivamente criar produtos e serviços que possam fidelizar, captar e satisfazer as expectativas e interesses de seus usuários finais.

Diante dessas dificuldades, percebe-se que elas deverão estar relacionadas ao sistema de organização, de navegação, de busca e de rotulagem, bem definidos por Morville; Rosenfeld (2006), dado o grande número de opções disponíveis, a arquitetura de informação pode determinar a permanência ou abandono dos sistemas virtuais pelos usuários.

Evidenciamos que a pesquisa não cobriu todas as funcionalidades do SIGAA; houve uma concentração nas funcionalidades obtidas a partir do "menu docente", portanto, ali deveriam haver funções de estrito interesse dessa comunidade de usuários.

Quanto à percepção da adequação da interface disponível aos usuários, percebe-se que, apenas $40 \%$ dos participantes da pesquisa a consideram "satisfatória"; há, portanto, uma grande necessidade de aprimoramento tendo-se em vista que, o inverso, $60 \%$ dos usuários têm restrições a essa interface. Todavia, o mesmo grupo percebe que a disposição (layout), das opções e funcionalidades, está planejada de forma que a produtividade seja favorecida. 
No grupo de questões para obterem-se impressões sobre a compreensão, densidade informacional e adaptabilidade, os participantes da pesquisa relataram que $66,7 \%$ não perceberam problemas no posicionamento das opções disponíveis. Contrastando com o fato do mesmo grupo considerar, em sua maioria, que a ferramenta não tem características adaptativas.

Quanto à questão sobre o uso de informações estatísticas fornecidas pelo SIGAA, obtivemos apenas duas variações de resposta "não uso" com $50 \%$ e "outros" com também $50 \%$, considerando-se que a questão era aberta e podiam ser fornecidas quaisquer respostas textuais, consideramos intrigante que $50 \%$, dos que usam as informações estatísticas, tenham respondido "outros", ao invés de explicitar o tipo de uso. Portanto, tratando-se da importância e necessidade de estudos de usabilidade, é recomendável que se faça avaliação do site, em função de verificar os ajustes recomendáveis a serem feitos no sistema. Assim, como afirmam Ferreira; Pitfhan, (2005, p.653): "Mesmo com a resolução dos problemas, outros estudos de usabilidade são recomendados, para que problemas não percebidos nestes testes, possam ser identificados futuramente, ou até mesmo, problemas gerados pelas alterações e reformulações sejam detectados antes do lançamento do site".

Observamos também que $53 \%$ dos participantes informaram que as informações pessoais do docente, devem ser exibidas constantemente.

Enquanto apenas $40 \%$ afirmaram que considera a interface satisfatória, esse mesmo grupo afirmou que as opções existentes cooperam na produtividade nas atividades do docente, tendo sido pontuado $60 \%$ positivamente para essa consideração. Percebe-se pela análise dos dados uma oportunidade de melhoria no SIGAA com relação à interface.

Considere-se também que $66,7 \%$ dos participantes acreditam não haver informações posicionadas incorretamente no SIGAA, o que contrasta diretamente com o que foi respondido anteriormente, na qual a maioria 73,3\% não possuem características adaptativas.

Apesar de percebermos problemas quanto a Al do SIGAA, expressa no conjunto de funcionalidades ofertadas uma baixa relevância para o usuário, e a maioria dos respondentes não verem características de adaptabilidade.

\section{Considerações Finais}

Com o propósito de fazer uma reflexão acerca do como os participantes docentes da pesquisa junto ao SIGAA se comportam, sobre o conhecimento, funcionalidades e o grau de satisfação com o uso da ferramenta, e a adequação de sua arquitetura da informação para o uso pelo usuário docente, foi o objetivo principal deste trabalho.

Consideramos que neste aspecto a prática do usuário docente no tocante ao contexto e conteúdo, os objetivos foram cumpridos, de acordo com as respostas obtidas dos docentes do Departamento de Ciências da Informação da UFC.

Verificando também o nível de dificuldades acentuadas por esses usuários no que foi expresso que há um difícil acesso e demora na realização de registros de reclamações.

Conforme a questão doze, quando indaga como as informações estatísticas sobre o SIGAA são úteis no trabalho, ficou revelado que há uma desinformação quanto à aplicabilidade das informações estatísticas geradas pelo SIGAA, já que nenhum docente que participou da pesquisa informou com clareza, que uso faz dessa funcionalidade.

Como há um grande volume de funcionalidades com baixo uso, como sinaliza a figura cinco, a questão seis indaga sobre a não utilização no portal docente, por exemplo, ambientes virtuais e produção intelectual, demonstrando assim que o docente deveria ter sido consultado para a decisão de quais elementos funcionais deveriam ser disponibilizados no SIGAA no "menu docente". O único grupo de funcionalidade que sempre é utilizado é o de ensino; todas as outras têm alto grau de rejeição pelo docente, no recorte da pesquisa.

Detectamos que o SIGAA tem problemas em sua AI, expressos em sua interface e no conjunto de funcionalidades, e que esses problemas impedem a ferramenta de alcançar seu potencial de contribuição para o trabalho docente. 
Fica evidente pela análise dos dados, e pelas conclusões a partir deles, que o SIGAA não teve um processo suficientemente robusto para a criação de sua arquitetura da informação. O usuário docente parece não ter sido consultado ou envolvido na criação do referido sistema. Assim, se confirma que houve uma falha no estudo do usuário docente relativo ao SIGAA.

Quanto a avaliação da interface feita pelos usuários docentes, expressaram como a necessidade mais urgente tornar mais clara as informações nas ferramentas disponíveis tais como

Concluímos que a ferramenta tem um potencial de contribuição ao docente em seu trabalho, todavia requer urgentes melhorias. Melhorias essas a serem diretamente apontadas pelos usuários, para que a Al do SIGAA possa convergir em direção as necessidades de informação dos usuários docentes do Departamento de Ciências da informação da Universidade Federal do Ceará.

\section{Referências}

AGNER, Luiz; SILVA, Fabio Luiz Carneiro Mourilhe. Uma introdução à arquitetura da informação: conceitos e usabilidade. PUC-Rio, 2003. Disponível em: https://profsergioxavier.files.wordpress.com/2012/08/introducao arquitetura informacao.pdf. Acesso em: 16 maio 2017.

ALMEIDA JÚNIOR, Osvaldo Francisco de. Mediação da informação: ampliando o conceito de disseminação. In: VALENTIM, Marta (Org.). Gestão da informação e do conhecimento no âmbito da ciência da informação. São Paulo: Polis: Cultura acadêmica, 2008.

BASTIEN, J. M. Christian; SCAPIN, Dominique L. Ergonomic Criteria for the Evaluation of Human-Computer interfaces. France: Institut National de recherche en informatique et en automatique, 1993.

BENTES PINTO, Virginia; TABOSA, Hamilton Rodrigues; VIDOTTI, Silvana Aparecida Borsetti Gregório. Arquitetura da informação: representação da informação de prontuário eletrônico do paciente. In: ENCONTRO NACIONAL DE PESQUISA EM CIÊNCIA DA INFORMAÇÃO, 12., 2011, Brasília. Anais [...]. Brasília: ANCIB, 2011. p. 2629-2642. Disponível em: http://repositorios.questoesemrede.uff.br/repositorios/bitstream/handle/123456789/2023/Arquitetura\%20\%20Bentes\%20Pinto.pdf? sequence=1. Acesso em: 27 dez. 2020.

CARDOSO, Olinda Nogueira Paes. Recuperação de Informação. INFOCOMP: Journal od Computer Center, v. 2, n. 1, nov. 2000. Disponível em: http://www.dcc.ufla.br/infocomp/index.php/INFOCOMP/article/view/46 Acesso em: 27 dez. 2020.

COSTA, Luciana Ferreira da; SILVA, Alan Curcino da; RAMALHO, Francisca Arruda. (Re) visitando os estudos de usuário: entre a tradição e o alternativo. DataGramaZero. v. 10, n. 4, ago. 2009. Disponível em: https://brapci.inf.br/index.php/res/v/6946. Acesso em: 27 dez. 2020.

COSTA, Maria de Fátima Oliveira; ALMEIDA JÚNIOR, Oswaldo Francisco de. Os conceitos de estudos de usuários e a visão do bibliotecário no processo de mediação da informação. In: CAVALCANTE, Lídia Eugenia; BENTES PINTO, Virginia; VIDOTTI, Silvana Aparecida Borsetti Gregório. Ciência da Informação e contemporaneidade: tessituras e olhares. Fortaleza: Ed. UFC, 2012.

COSTA, Maria de Fátima Oliveira. Estudos de usuários da informação: ensino e aprendizagem no Brasil. Fortaleza: Edições UFC, 2016.

DE SOUZA, Osvaldo; TABOSA, Hamilton Rodrigues. Virando a Página: um novo conceito de acessibilidade na web para deficientes visuais. Informação \& Sociedade: Estudos, João Pessoa, v. 24, n. 1, p. 145-161, 2014. Disponível em: https://periodicos.ufpb.br/ojs2/index.php/ies/article/view/16366/10935. Acesso em: 27 dez. 2020.

DE SOUZA, Osvaldo. A usabilidade na perspectiva do uso da informação: estatísticas das pesquisas sobre o tema no Brasil. Informação \& Sociedade: Estudos, João Pessoa, v. 25, n. 1, p. 159-172, 2015. Disponível em:

https://periodicos.ufpb.br/ojs/index.php/ies/article/view/159/13196. Acesso em: 27 dez. 2020.

ELLIS, David. A behavioral model for information retrieval system design. Journal of Documentation Science. Cambridge, n. 15, p. 237247, 1989.

ESPANTOSO, José Juan Peón. A gestão de competências dos arquitetos da informação nas organizações. DataGramaZero, v. 11, n. 5, out. 2010. Disponível em: https://brapci.inf.br/index.php/res/v/7195. Acesso em: 27 dez. 2020.

FERREIRA, Ana Maria Jensen; VECHIATO, Fernando Luiz; VIDOTTI, Silvana Aparecida Borsetti Gregório. Arquitetura da informação de web sites: um enfoque à universidade aberta à Terceira idade (UNATI). Revista de Iniciação Científica da FFC, Marília, v. 8, n. 1, p. 114129, 2008. Disponível em: https://revistas.marilia.unesp.br/index.php/ric/article/view/184. Acesso em: 27 dez. 2020.

FERREIRA, Sueli Mara; PITHAN, Denise Nunes, Estudo de Usuários e de Usabilidade na Biblioteca INFOHAB: relato de uma experiência. In: SIMPÓSIO INTERNACIONAL DE BIBLIOTECAS DIGITAIS, 3, 2005, São Paulo. Anais [...]. São Paulo: UFSC, 2005. Disponível em: http://eprints.rclis.org/10483/. Acesso em: 27 dez. 2020.

FISCHER, Gustavo Daudth; ARAÚJO, Luciana C. S. Conceitos e características do design estratégico como provocações iniciais à arquitetura da informação. In: ENCONTRO BRASILEIRO DE ARQUITETURA DE INFORMAÇÃO, 4, 2010, São Paulo. Anais [...]. São Paulo: USP, 2010.

THE INFORMATIONS ARCHITECTURE INSTITUTE: IAI Institute. What is Information Arquitecture? Trad. 2010. Disponível em: http://iainstitute.org/en/learn/resources/what is ia.php. Acesso em: $27 \mathrm{dez} .2020$.

ILHARCO, Fernando. Filosofia da Informação: uma introdução à informação como fundação da ação, da comunicação e da decisão. Lisboa: Universidade Católica Editora, 2003. 
MANNING, Christopher D.; RAGHAVAN, Prabhakar; SCHÜTZE, Hinrich. Relevance feedback and query expansion. In: MANNING, Christopher D.; RAGHAVAN, Prabhakar; SCHÜTZE, Hinrich. An introduction to information retrieval. England: Cambridge University Press, 2009. p. 177-194.

MORVILLE, Peter; ROSENFELD, Louis. Information Achitecture for the world wide web. Sebastopol: O'Reilly, 2006.

NIELSEN, Jackob. Projetando Websites: designing Web usability. Rio de Janeiro: Campus, 2000.

PIEROZZI JÚNIOR, Ivo; GOMES, Eliane Gonçalves; ALENCAR, Maria de Cléofas Faggion; CARVALHO, Carlos Alberto de. Análise de dinâmica de uso e de desempenho: o caso do web site da Embrapa Monitoramento por Satélite. Ci. Inf., Brasília, v. 32, n. 1, p. 102-114, 2003. Disponível em: http://revista.ibict.br/ciinf/article/view/1024/1079. Acesso em: 27 dez. 2020.

SALTON, Gerard; YANG C.S. On the specification of term values in automatic indexing. Journal of Documentation, v. 29. n. 4. p. 351-372, 1973.

SARACEVIC, Tefko. Ciência da informação: origem, evolução e relações. Perspectivas em Ciência da Informação, Belo Horizonte, v. 1, n. 1, p. 41-62, jan./jun. 1996. Disponível em: http://portaldeperiodicos.eci.ufmg.br/index.php/pci/article/view/235/22. Acesso em: 27 dez. 2020 .

SIGAA UFC. Sistema Integrado de Atividades Acadêmicas. Versão UFC. Disponível em: https://si3.ufc.br/sigaa/verTelaLogin. Acesso em: 27 dez. 2020

SILVA, Nóbrega da; DUARTE, Emeide Nóbrega. Instrumento para diagnostico da Gestao da Informaçao e do Conhecimento (GIC) para Bibliotecas Universitárias. Ciência da Informação em Revista, Maceió, v. 2, n. 2, p. 54-66, maio/ago. 2015. Disponível em: https://www.seer.ufal.br/index.php/cir/article/view/1756/1367. Acesso em: 27 dez. 2020

SILVA, Patrícia M.; DIAS, Guilherme Ataíde. A arquitetura da informação centrada no usuário: estudo do website da Biblioteca Virtual em Saúde (BVS). Encontros Bibli: Revista Eletrônica de Bibliotecon. Ci. Inf., Florianópolis, v. 13, n. 26, jul/dez. 2008. Disponível em: https://periodicos.ufsc.br/index.php/eb/article/view/1518-2924.2008v13n26p119/6647. Acesso em: 27 dez. 2020.

SHAW, Ian S.; SIMÕES, Marcelo Godoy. Controle e modelagem Fuzzy. São Paulo: Edgard Blücher, 1999.

VIDOTTI, Silvana Aparecida Borsetti Gregorio; SANCHES, Silviane Aparecida. Arquitetura da informação em web site. In: SIMPÓSIO INTERNACIONAL DE BIBLIOTECAS DIGITAIS, 2, 2004, Campinas. Anais [...]. Campinas: UNICAMP, 2004. Disponível em: http://www.bibliotecadigital.unicamp.br/document/?code=8302\&opt=1. Acesso em: 27 dez. 2020.

WURMAN, Richard Saul. Ansiedade de Informação 2: um guia para quem comunica e dá instruções. São Paulo: Ed. de Cultura, 2005.

Artigo submetido em: 08/05/2020.

Aceito em: 17/12/2020.

\section{UFCa UNIVERSIDADE}

Centro de Ciências Sociais Aplicadas

Mestrado Profissional em Biblioteconomia

Este periódico é uma publicação do Programa de Pós-Graduação em Biblioteconomia da Universidade Federal do Cariri em formato digital e periodicidade quadrimestral 